\title{
HETEROGENEOUS TRADERS, PRICE-VOLUME SIGNALS, AND COMPLEX ASSET PRICE DYNAMICS
}

\author{
FRANK H. WESTERHOFF
}

Received 21 June 2004

We seek to develop a novel asset pricing model with heterogeneous traders. Fundamental traders expect that asset prices converge towards their intrinsic values, whereas chart traders rely on both price and volume signals to determine their orders. To be precise, the larger the trading volume, the more they believe in the persistence of the current price trend. Simulations of our nonlinear deterministic model reveal that interactions between fundamentalists and chartists may cause intricate endogenous price fluctuations. Contrary to the intuition, we find that chart trading may increase market stability.

\section{Introduction}

As shown by the chartist-fundamentalist approach, asset prices are at least partially driven by an endogenous nonlinear law of motion. Complex (chaotic) price dynamics may arise due to interactions between speculators who rely on technical and fundamental trading rules to determine their investment positions. Technical analysis is a trading method that aims to identify trading signals from past price trends. A common belief is that such positive feedback rules tend to drive prices away from fundamentals. By contrast, fundamental trading tends to push prices towards fundamentals. The concept of fundamental analysis is in fact based on the premise that the gap between prices and fundamentals will decline over time.

We briefly review some important models which have been developed in the literature so far. Day and Huang $[6,12]$ present a setup in which fundamentalists use a nonlinear trading rule. The larger the distance between the price and its fundamental value, the more strongly the fundamentalists bet on mean reversion. If prices are close to fundamentals, then the chartists destabilize the market. With increasing mispricing, however, stabilizing fundamentalists dominate the market. A strong feature of this model is that it is able to produce irregular motion between bull and bear markets. Contributions which also explore nonlinear trading rules include, for example, $[4,5,9,13]$.

Another interesting framework has been proposed by de Grauwe et al. [7]. They argue that fundamentalists are heterogeneous with respect to their perception of the 
fundamental value. If the price is equal to its fundamental value, then half of the fundamentalists underestimate the fundamental value and the other half overestimate the fundamental value. The net demand of fundamentalists is therefore zero. But as the distance between the price and its fundamental value grows, the net position of the fundamentalists becomes larger and larger, implying that eventually the destabilizing behavior of the chartists is countered.

Profits are presumably what speculators care about most. In [2, 3], agents switch between cheap naive and expensive sophisticated predictors. Their behavior is rational in the sense that they tend to prefer predictors which have been profitable in the past. Note that when prices are close to fundamentals, costly fundamental predictors perform poorly. As a result, cheap technical trading is then rather popular. On the other hand, fundamental analysis tends to outperform technical analysis when prices are far away from fundamentals. Since the market impact of the strategies varies over time, erratic price fluctuations may arise.

Within the models of Lux $[14,15]$, speculators also select between technical and fundamental trading rules based on the rules' past profit differentials. But Lux furthermore considers social interactions between the agents, such as herding behavior. Influenced by the majority opinion, the mood of the chartists may turn optimistic or pessimistic. Buffeted with noise, this setup has the power to produce price dynamics which closely match the stylized facts of financial markets (Lux and Marchesi [16]).

The goal of this paper is to describe a novel, yet quite natural, mechanism which may lead to endogenous price motion. (A thorough understanding of the possible origins of price fluctuations is, of course, quite important. For instance, it may help regulators to design more efficient markets [19].) As reported in many manuals about technical analysis (e.g., Murphy [17]), trading volume is an important confirmation signal of price action: the larger the trading volume is, the more trustworthy a given price trend is. Guided by such evidence, we develop a simple deterministic asset pricing model in which chartists pay attention to price-volume signals. Since the chartists condition their orders jointly on prices and volume, their trading rule is nonlinear. As it turns out, our model has the power to produce complex price dynamics. Simulations reveal that the price circles in an intricate way around its fundamental value without any apparent tendency to converge. Moreover, we find that technical trading may improve market efficiency. If fundamentalists trade very aggressively, the existence of a limited number of chartists may ensure the stability of financial markets.

The rest of this paper is organized as follows. In Section 2, we present a deterministic asset pricing model with chartists and fundamentalists. In Section 3, we discuss the dynamics of our model. In Section 4, we test the robustness of our results by modifying the behavior of the chartists. In Section 5, we conclude the paper and summarize our main findings.

\section{The model}

In this section, we develop a stylized asset pricing model with three types of agents: market makers, fundamentalists, and chartists. The job of the market makers is to quote prices and to mediate transactions out of equilibrium. Depending on the excess demand $E$ of 
the speculators in period $t$, they set the log of the price $P$ for period $t+1$ as

$$
P_{t+1}=P_{t}+E_{t}
$$

If the excess demand is positive, the market makers supply the asset from their inventory and increase the price. If $E<0$, they accumulate inventory and decrease the price.

The excess demand of the speculators is given as the sum of the orders of the fundamentalists and of the chartists, that is,

$$
E_{t}=N\left(D_{t}^{F}+D_{t}^{C}\right)
$$

$N$ is a positive parameter and captures the aggressiveness of the speculators. An increase in $N$ may also be interpreted as an increase in the number of speculators. $D^{F}$ and $D^{C}$ stand for the orders generated by fundamental and technical trading rules, respectively. Clearly, the total demand submitted by fundamental (technical) traders is $N D^{F}\left(N D^{C}\right)$.

Fundamental traders believe that prices move towards their fundamental values. Thus, they buy assets that are undervalued and sell them when they are overvalued. The orders generated by fundamental trading rules may be expressed as

$$
D_{t}^{F}=\left(F-P_{t}\right)
$$

where $F$ is the log of the fundamental value. Note that the demand of the fundamental trading rule is proportional to the mispricing. In agreement with the literature, we assume that the agents correctly perceive the (constant) fundamental value of the asset.

The basic idea of technical analysis is to exploit price trends. As reported by Day and Huang [6], chartists enter the market when the price is high under the belief that the price will go up, and exit the market when the price is low under the belief that the price will go down. However, many technical traders argue that one should also take the trading volume into account since it provides clues as to the reliability of a given trading signal [17]. To be precise, chartists claim that high trading volume indicates a robust signal, whereas low volume indicates a weak signal. The orders due to technical analysis may thus be formalized as

$$
D_{t}^{C}=\left(P_{t}-F\right) V_{t-1}
$$

with

$$
V_{t-1}=N\left|D_{t-1}^{F}\right|+N\left|D_{t-1}^{C}\right|
$$

as the definition for the trading volume. Suppose, for instance, that prices are bullish $(P>F)$. Then, technical analysis produces a buying signal. However, the strength of the buying signal increases with the trading volume. Note that (2.4) is a nonlinear, yet very natural, trading rule.

Without loss of generality, we set $F=0$. The recurrence relation that determines the dynamics of the model, obtained by combining (2.1)-(2.5), is given as

$$
P_{t+1}=P_{t}\left(1-N+2 N^{2}\left|P_{t-1}\right|\right),
$$

which is a second-dimensional deterministic nonlinear map. 


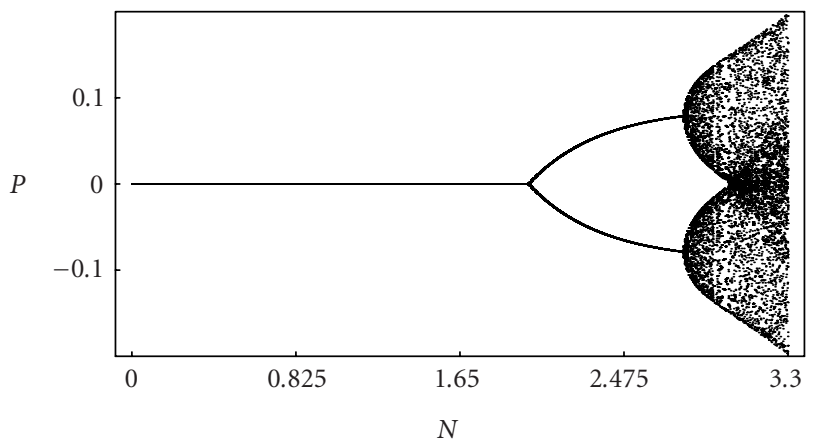

Figure 3.1. Bifurcation diagram for parameter $N$. Parameter $N$ is increased from 0 to 3.3 in 500 steps. Each time, prices are plotted for $t=1001-1100$.

\section{The dynamics}

Since the model has only one parameter, its dynamics can easily and completely be characterized with the help of a bifurcation diagram. The bifurcation diagram presented in Figure 3.1 is constructed as follows. We increase the parameter $N$ from 0 to 3.3 in 500 discrete steps. Each time, we calculate 1100 data points. To exclude possible transient phases of the trajectory, only the last 100 observations are plotted. Hence, Figure 3.1 displays the dynamical outcome of our model for increasing values of $N$. A bifurcation diagram is obviously a powerful graphical tool to visualize the properties of a nonlinear dynamical system.

What are the results? We immediately see that the price converges to a unique fixed point equal to the fundamental value $F=0$ for $0<N<2$. At $N=2$, a period-doubling bifurcation occurs. That is, the system switches back and forth between two states, one above and one below its fundamental value. Note that as $N$ further increases, both prices of the period two-cycle become more distant from the fundamental value. A second bifurcation occurs around $N=2.8$. For $N>2.8$, the price dynamics is either quasiperiodic or even chaotic. Moreover, deviations from the fundamental value also become larger. At about $N=3.35$, the system explodes.

Phase space plots allow us to further investigate the dynamics. In Figure 3.2, we plot the price in period $t$ against the price in period $t-1$ for nine different values of $N((\mathrm{a})$ $N=2$, (b) $N=2.5$, (c) $N=2.8$, (d) $N=2.9$, (e) $N=3.05$, (f) $N=3.1$, (g) $N=3.15$, (h) $N=3.25$, and (i) $N=3.32$ ). A transient phase of 1000 time steps is again omitted. Now, we can clearly see that the system moves from a fixed point to a period two-cycle, then to quasiperiodic behavior, and finally to chaotic dynamics. (Remember that a time series is said to be chaotic if its time path is sensitive to a microscopic change in the value of the initial conditions. Moreover, a chaotic time series typically displays complex structure in phase space, i.e., a so-called strange attractor emerges. While the former property may be identified by a positive Lyapunov exponent, a strange attractor results in a noninteger correlation dimension (see, e.g., [18]).) Note that the panel in (i) displays a so-called strange attractor with a correlation dimension $\mathrm{CD}=1.422$. Since the corresponding Lyapunov exponent is $\mathrm{L}=0.465>0$, we can indeed conclude that the price dynamics is chaotic. 


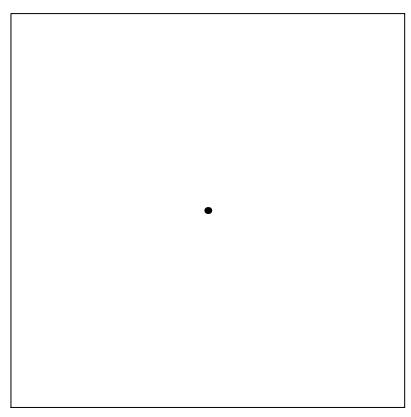

(a)

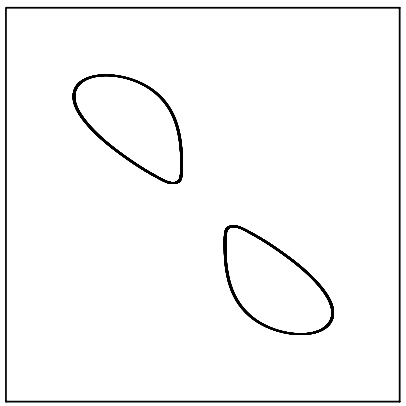

(d)

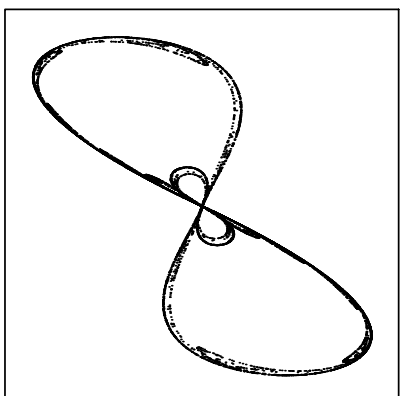

(g)

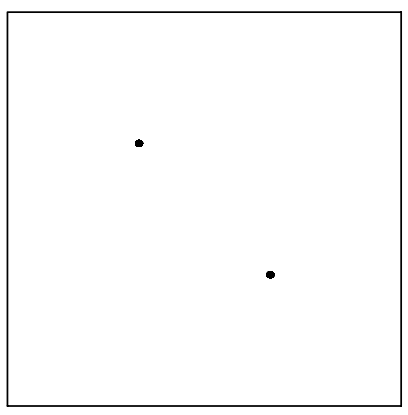

(b)

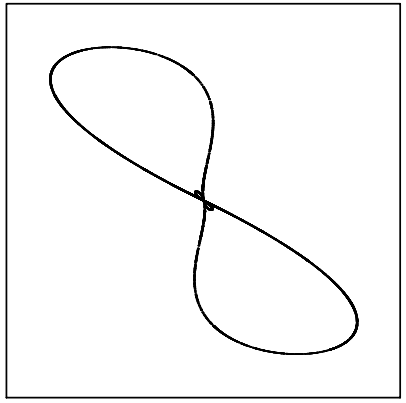

(e)

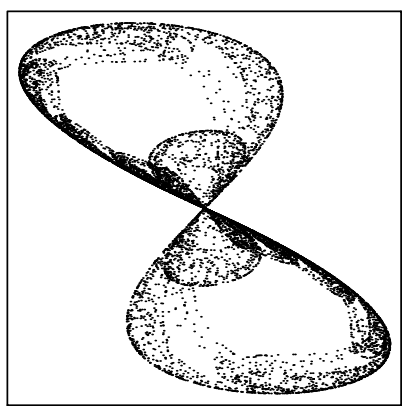

(h)

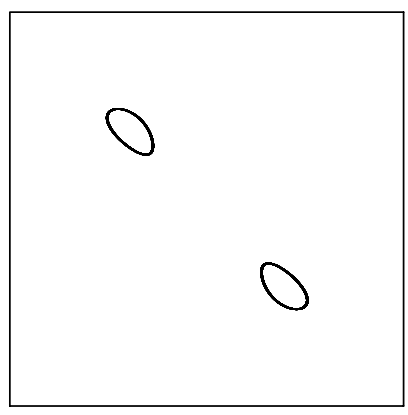

(c)

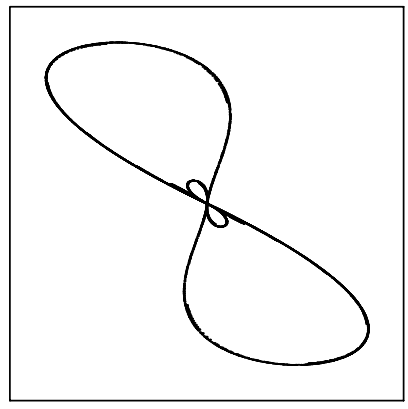

(f)

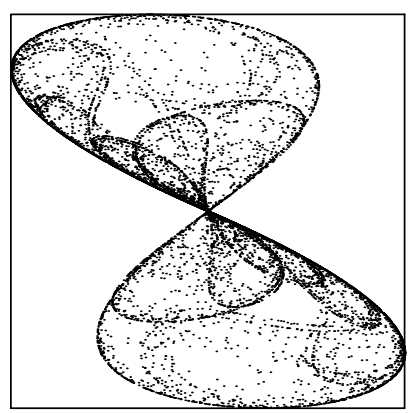

(i)

Figure 3.2. The dynamics is phase space. Prices in period $t$ are plotted against prices in period $t-1$ for (a) $N=2$, (b) $N=2.5$, (c) $N=2.8$, (d) $N=2.9$, (e) $N=3.05$, (f) $N=3.1$, (g) $N=3.15$, (h) $N=3.25$, and (i) $N=3.32$. A transient phase of 1000 observations has been omitted. 
As ventured by Friedman [10], profitable speculation-buying when prices are low and selling when prices are high-will always stabilize the markets. As a result, the impact of destabilizing speculators can be neglected since they will lose their money and drop out of the market. However, Baumol [1] showed that Friedman may not necessarily be right. He constructed a simple second-order difference equation model in which a "buying low and selling high" trading strategy may increase the frequency and amplitude of price fluctuations. The difference between the two standpoints is that Friedman's argument takes only into account the levels of the variables, yet neglects their time derivatives. But as demonstrated by Baumol, the price path is dependent on both. A similar finding is reported by de Long et al. [8] in a model with fully rational speculators and positive feedback traders. Their main argument is that fully rational speculators may exploit positive feedback traders by inducing a positive price trend. When feedback traders jump on the bandwagon, rational speculators can sell at higher prices. More importantly, surveying theoretical, empirical, and experimental evidence, Hommes [11] concludes that both destabilizing technical and stabilizing fundamental trading rules may survive evolutionary competition in financial markets, that is, neither strategy is driven out of the market. Especially during a bubble period, technical analysis may produce significant profits.

We clarify the role of the speculators within our setup. Suppose first that only fundamentalists are active, that is, $D^{C}=0$. Then, the law of motion becomes

$$
P_{t+1}=P_{t}(1-N)
$$

Obviously, prices converge to the fundamental value for $0<N<2$ and explode for $N>2$. If fundamentalists are too aggressive, they in fact drive prices away from fundamentals. But note that Figures 3.1 and 3.2 reveal that if both chartists and fundamentalists are present in the market, prices do not explode in the parameter region $2<N<3.35$. So, is the behavior of the chartists stabilizing? Suppose now that only chartists are active, that is, $D^{F}=0$. Then, prices evolve according to

$$
P_{t+1}=P_{t}\left(1+N^{2}\left|P_{t-1}\right|\right)
$$

Since the expression in the bracket is always larger than 1, prices run away from fundamentals. The behavior of the chartists is thus destabilizing. To sum up, even if the isolated behavior of fundamentalists and chartists is destabilizing, their joint impact may be stabilizing. This puzzling finding furthermore points out that it is important to study models with heterogeneous interacting agents.

Now, we inspect the workings of the model in more detail. Figure 3.3 illustrates the dynamics in the time domain for $N=3.32$. The panels in (a), (b), (c), and (d) present a sequence of 50 observations of the price in period $t$, the orders of the fundamentalists in period $t-1$, the orders of the chartists in period $t-1$, and the trading volume in period $t-2$, respectively. As visible in (a), the price hovers erratically around its fundamental value without any apparent tendency to converge. The trading signals needed to keep asset prices in motion are generated by the agents themselves. Clearly, it is the interaction between traders that creates endogenous dynamics. Since there are no 
fundamental shocks (the fundamental value is constant), volatility and trading volume are excessive.

The panels in (b), (c), and (d) further explain the trading behavior of the two groups. Remember that for $N=3.32$, prices would explode in the absence of chartists. Fundamentalists are overreacting to mispricings and thus their orders trigger a too-strong price adjustment. However, if both groups are active, the positions of the fundamentalists are partially countered by the demand of the chartists. In fact, the two groups always trade in different directions. Note that as the fundamentalists drive the price away from its fundamental value, the trading volume tends to increase. As a result, the chartists believe more strongly in their trading signals and submit larger orders. Technical trading orders eventually offset the orders of the fundamentalists and the system temporarily produces smaller price changes. But then the pattern repeats itself, yet in an intricate manner. (In [20], it is demonstrated that if one adds dynamic noise to the system equations, then the model has the power to mimic some important stylized facts of financial markets. In particular, the model may simultaneously generate bubbles and crashes, excess volatility, fat tails for the distribution of the returns, uncorrelated price changes, and volatility clustering.)

\section{Robustness}

We finally explore whether our findings are robust. According to (2.4), chartists believe in the persistence of bull and bear markets. When the price is above (below) its fundamental value, they assume that the price will continue to climb (descend). Although their demand is positively correlated with price changes, the behavior of the chartists is often directly modeled as trend extrapolative. An alternative specification of the technical trading rule may thus be

$$
D_{t}^{C}=\left(P_{t}-P_{t-1}\right) V_{t-1}
$$

Now, the chartists base their orders on the most recent (log) price change. The larger the price trend, the stronger the trading signal appears. Such behavior is indeed quite popular among chartists (Murphy [17]).

If markets do not display lasting price trends, then technical traders prefer oscillator analysis [17]. De Grauwe et al. [7] suggest, for instance, the following double crossover method to describe the behavior of chartists in foreign exchange markets:

$$
D_{t}^{C}=\left\{\left(P_{t}-P_{t-1}\right)-0.5\left(P_{t}-P_{t-2}\right)\right\} V_{t-1}
$$

The first term of the right-hand side of (4.2) stands for a short-term moving average (i.e., a one-period price change), while the second term stands for a longer-term moving average (i.e., a two-period price change). For instance, a buying signal is generated when the short-term moving average crosses the long-term moving average from below.

Figure 4.1 checks whether our findings are robust with respect to different technical analysis trading rules. The panel in (a) shows a bifurcation diagram for our model in 


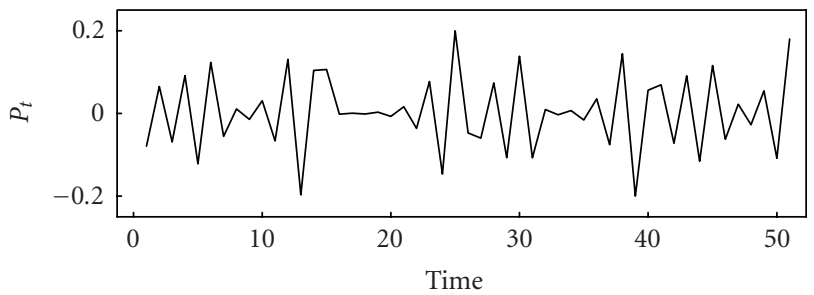

(a)

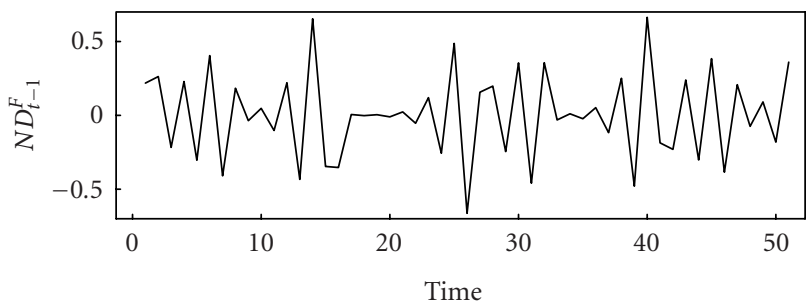

(b)

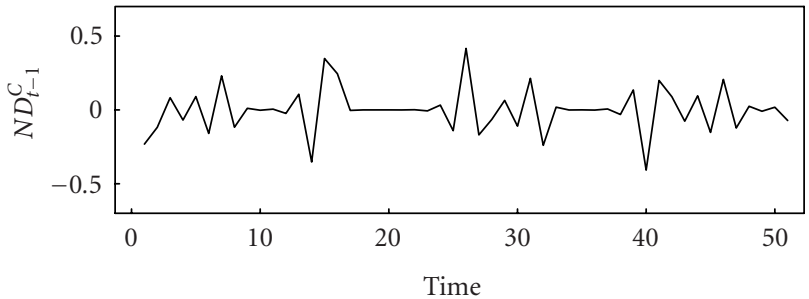

(c)

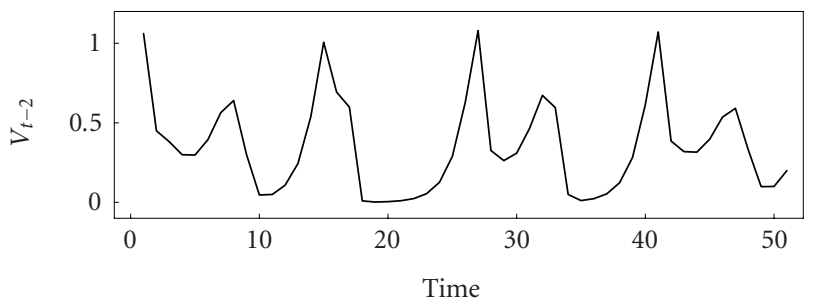

(d)

Figure 3.3. The dynamics in the time domain for $N=3.32$. The panels in (a), (b), (c), and (d) show a sequence of 50 observations of the price in period $t$, the orders of the fundamentalists in period $t-1$, the orders of the chartists in period $t-1$, and the trading volume in period $t-2$, respectively. 


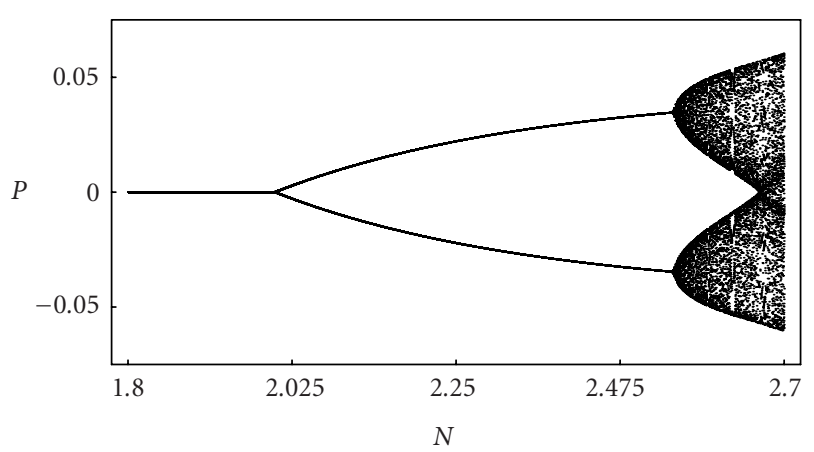

(a)

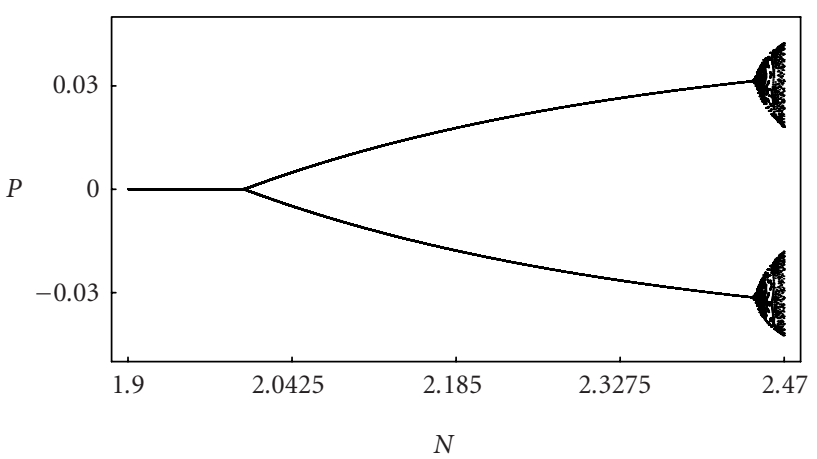

(b)

Figure 4.1. Robustness of the dynamics. The panel in (a) shows a bifurcation diagram for the model with the technical trading rule (4.1). In (b), the technical trading rule (4.2) is used. The parameter $N$ is increased as indicated on the axis. The remaining setup is as in Figure 3.1.

which we have substituted (2.4) by (4.1). The panel in (b) shows the same, except that we now use (4.2) to approximate technical analysis. In both cases, we first observe that the price converges towards its fundamental value $(0<N<2)$. For $N>2$, a period two-cycle arises, and if $N$ is sufficiently large, even more complex price motion emerges. Overall, we are tempted to conclude that the nonlinear mechanism proposed in this paper is able to produce endogenous price fluctuations and that the behavior of chartists may not be bad for market efficiency per se.

\section{Conclusions}

Financial markets are excessively volatile and frequently display severe bubbles and crashes. Models with interacting heterogeneous speculators have proven their ability in explaining complex asset price behavior. The aim of this paper is to investigate a novel, 
yet quite natural, nonlinear mechanism that arises from the fact that chartists typically condition their price signal on the trading volume. In other words, technical traders trust the current price trend more strongly if it is supported by a high trading volume. For simplicity, the behavior of the fundamentalists and of the market makers is expressed in linear terms. We find that our simple setup is able to generate endogenous complex price motion, that is, prices fluctuate in an intricate manner around their intrinsic values. Furthermore, we find that the behavior of the chartists may stabilize the markets. If fundamentalists overreact to mispricings, chartists counterbalance part of their transactions so that market makers adjust the prices less strongly. Especially when prices are on the verge of instability — a situation in which trading volume is high — chart-generated orders calm down the market.

\section{References}

[1] W. Baumol, Speculation, profitability, and stability, Review of Economics and Statistics 39 (1957), 263-271.

[2] W. A. Brock and C. H. Hommes, A rational route to randomness, Econometrica 65 (1997), no. 5, 1059-1095.

[3] _ Heterogeneous beliefs and routes to chaos in a simple asset pricing model, J. Econom. Dynam. Control 22 (1998), no. 8-9, 1235-1274.

[4] C. Chiarella, The dynamics of speculative behaviour, Ann. Oper. Res. 37 (1992), no. 1-4, 101123.

[5] C. Chiarella, R. Dieci, and L. Gardini, Asset price dynamics in a financial market with fundamentalists and chartists, Discrete Dyn. Nat. Soc. 6 (2001), 69-99.

[6] R. Day and W. Huang, Bulls, bears and market sheep, Journal of Economic Behavior and Organization 14 (1990), 299-329.

[7] P. De Grauwe, H. Dewachter, and M. Embrechts, Exchange Rate Theory-Chaotic Models of Foreign Exchange Markets, Blackwell, Oxford, 1993.

[8] B. De Long, A. Shleifer, L. Summers, and R. Waldmann, Positive feedback investment strategies and destabilizing rational speculation, Journal of Finance 45 (1990), 379-395.

[9] D. Farmer and S. Joshi, The price dynamics of common trading strategies, Journal of Economic Behavior and Organization 49 (2002), 149-171.

[10] M. Friedman, The case for flexible exchange rates, Essays in Positive Economics (M. Friedman, ed.), University of Chicago Press, Illinois, 1953, pp. 157-203.

[11] C. H. Hommes, Financial markets as nonlinear adaptive evolutionary systems, Quant. Finance 1 (2001), no. 1, 149-167.

[12] W. Huang and R. Day, Chaotically switching bear and bull markets: The derivation of stock price distributions from behavioral rules, Nonlinear Dynamics and Evolutionary Economics (R. Day and P. Chen, eds.), Oxford University Press, Oxford, 1993, pp. 169-182.

[13] H. Li and J. B. Rosser Jr., Emergent volatility in asset markets with heterogeneous agents, Discrete Dyn. Nat. Soc. 6 (2001), 171-180.

[14] T. Lux, Herd behavior, bubbles and crashes, Economic Journal 105 (1995), 881-896.

[15] - Time variation of second moments from a noise trader/infection model, J. Econom. Dynam. Control 22 (1997), no. 1, 1-38.

[16] T. Lux and M. Marchesi, Scaling and criticality in a stochastic multi-agent model of a financial market, Nature 397 (1999), 498-500.

[17] J. Murphy, Technical Analysis of Financial Markets, New York Institute of Finance, New York, 1999. 
[18] J. B. Rosser Jr., From Catastrophe to Chaos: A General Theory of Economic Discontinuities. Vol. 1: Mathematics, Microeconomics, and Finance, 2nd ed., Kluwer, Massachusetts, 2000.

[19] F. Westerhoff, Speculative markets and the effectiveness of price limits, Journal of Economic Dynamics and Control 28 (2003), 493-508.

[20] , Technical analysis based on price-volume signals and the power of trading breaks, Discussion Paper 2004/03, University of Osnabrueck, Germany, 2004.

Frank H. Westerhoff: Department of Economics, University of Osnabrueck, Rolandstrasse 8, 49069 Osnabrueck, Germany

E-mail address: fwesterho@oec.uni-osnabrueck.de 


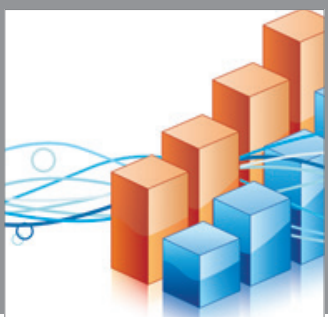

Advances in

Operations Research

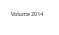

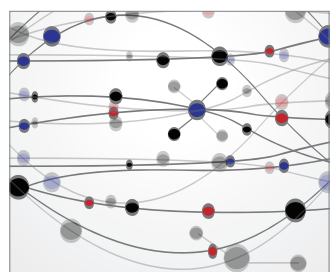

\section{The Scientific} World Journal
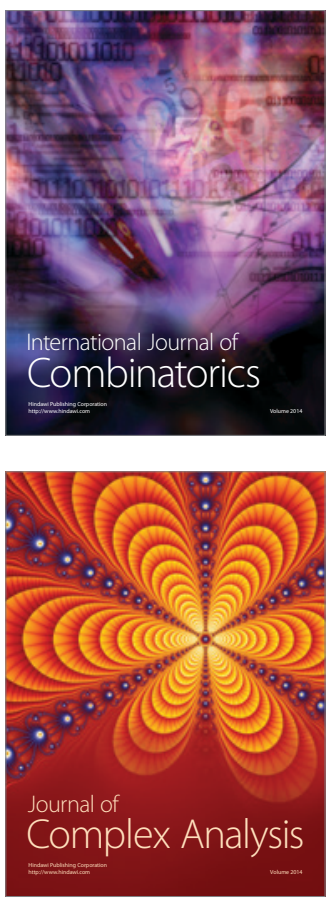

International Journal of

Mathematics and

Mathematical

Sciences
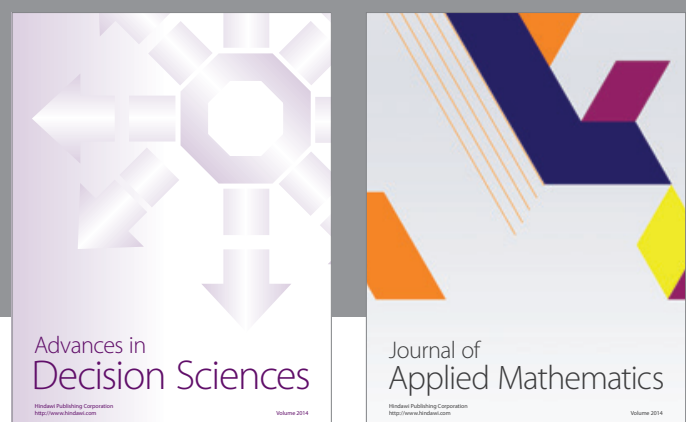

Journal of

Applied Mathematics
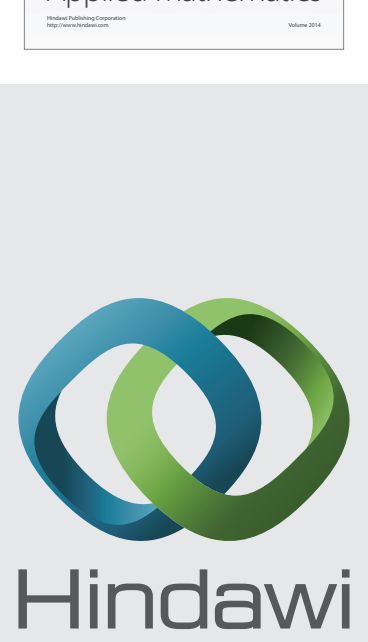

Submit your manuscripts at http://www.hindawi.com
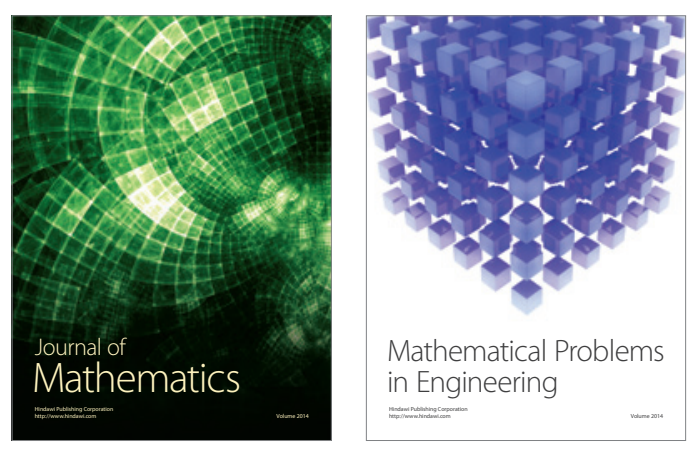

Mathematical Problems in Engineering
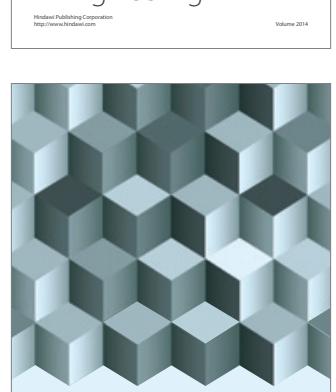

Journal of

Function Spaces
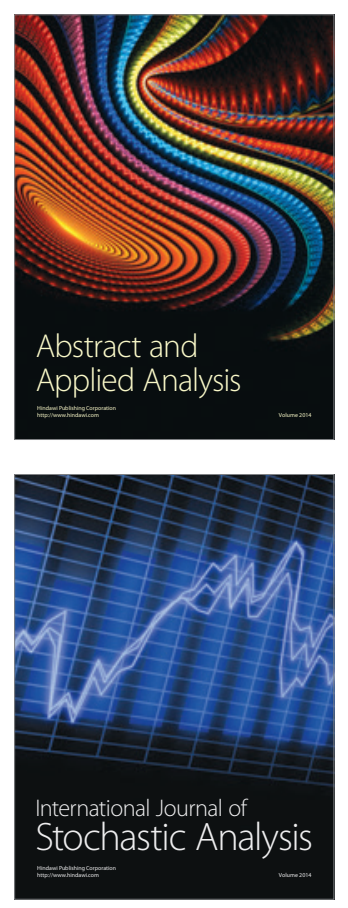

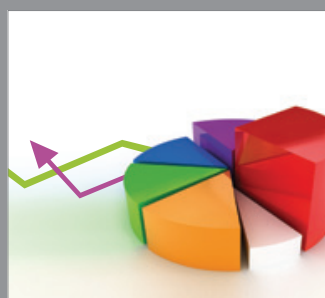

ournal of

Probability and Statistics

Promensencen
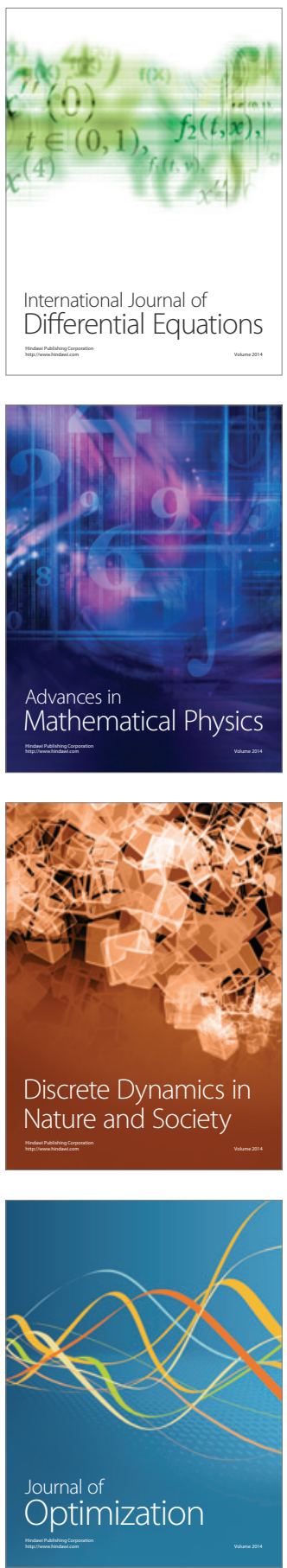